\title{
Prácticas comerciales entre migrantes africanos wolofs en Argentina: aportes para el análisis
}

\section{Commercial Practices among African Wolof Migrants in Argentina: Contributions to an Analysis}

\author{
M. LUZ ESPIRO \\ Universidad Nacional de La Plata, Argentina
}

Resumen: En este artículo analizo la dimensión laboral de la migración senegalesa contemporánea desde una perspectiva antropológica, para profundizar en la experiencia de fabricación artesanal de bijouterie entre los wolofs. Abordo su organzación social tradicional y caracterizo su sistema de estratificación hereditario, así como las identificaciones laborales, especialmente en el estatus de los ñeeño (artesanos y griots). Se trata de un marco de referencia vigente en la sociedad senegalesa, tanto en su origen como en el contexto migratorio. Seguí una metodología etnográfica con migrantes senegaleses en Argentina entre 2012 y 2018, y en Senegal en 2017, junto con una revisión bibliográfica especializada.

Palabras clave: migración senegalesa; trabajo; wolof; Argentina; ñeeño.

Recepción: 24 de marzo de 2020. / Aceptación: 19 de junio de 2020. 
Abstract: In this article I analyze the labor dimension of contemporary Senegalese migration from an anthropological perspective, in order to deepen the experience of handmade bijouterie among the Wolofs. I study its traditional social organization and characterize its system of hereditary stratification, as well as its work-related identifications, especially among the Nyeenyo (craftsmen and griots). This provides a frame of reference for Senegalese society, both in the context of origin and migration. I applied an ethnographic methodology with Senegalese migrants in Argentina between 2012 and 2018, and in Senegal in 2017, together with a review of specialized literature.

Keywords: Senegalese migration; work; Wolof; Argentina, Nyeenyo.

\section{Introducción}

Este trabajo propone un acercamiento antropológico a la dimensión laboral de la migración senegalesa, un flujo de movilidad africana reciente que viene creciendo en América del Sur desde principios del siglo XXI (OIM 2017). El objetivo es aproximarnos a ciertas adscripciones identitarias que permiten ampliar el análisis de sus dinámicas comerciales en la sociedad receptora, particularmente en Argentina. ${ }^{1}$

En un trabajo anterior argumentaba que algunos de estos migrantes varones manifiestan tener experiencia previa en la producción artesanal y en la comercialización de bijouterie como parte de una crianza moldeada por disposiciones étnicas, de clase $^{2}$ y ocupacionales específicas que sitúa sus prácticas co-

${ }^{1}$ Este artículo se desprende de mi tesis doctoral "Trayectorias laborales de migrantes senegaleses en La Plata y Puerto Madryn: una etnofotografía de los imaginarios y prácticas en torno al trabajo (2012-2018)”, Universidad Nacional de La Plata, 2019. Dirigida por las doctoras Bernarda Zubrzycki (Universidad Nacional de La Plata) y Ana Luiza Carvalho da Rocha (Universidade Federal do Rio Grande do Sul). Financiada por dos becas de posgrado UNLP y por proyectos de investigación acreditados (PICT 2012/ 0074, PIP-CONICET 0018, PID 11/N827) (Espiro 2019c).

${ }^{2}$ Entiendo la clase en términos de Thompson, como relación, como proceso, experiencias sociales comunes mediatizadas de algún modo por las relaciones de producción (Wood 1983). 
merciales en destino como la adaptación de una matriz tradicional, condicionada por las lógicas del capitalismo flexible (Espiro 2019a). En el presente artículo retomo esta consideración para postular que dicha matriz forma parte de una configuración cultural africana ${ }^{3}$ que, en su articulación histórica con la configuración europea y la musulmana, constituye la urdimbre que permite comprender la emergencia y las características de los flujos migratorios senegaleses actuales.

En las páginas siguientes profundizo específicamente en la organización social wolof tradicional como parte de esa configuración cultural africana. Me focalizo en su sistema de estratificación, y en las identificaciones étnico-laborales que ha habilitado, como marco de referencia vigente en las prácticas comerciales contemporáneas de los migrantes senegaleses. Se trata de un aspecto poco atendido por las investigaciones europeas y latinoamericanas, en comparación con el estudio del legado colonial y la influencia del islam negroafricano en esta migración (Coulon 1981; O’Brien 2002; Bava 2003; Riccio 2004; López de Mesa Samudio 2008; Iniesta 2009a y 2009b; Costa Dias 2009; Fall 2011; Guèye y Seck 2011; Zubrzycki 2011; Gentili 2012; Massó Guijarro 2014; Babou 2015; Ceamanos 2016; De Diego González 2019). Por ello, otro propósito de este artículo es aportar conocimiento en español sobre un tema vacante, relativo a aspectos socioidentitarios de este grupo migratorio que tienen una función relevante en sus disposiciones dentro del campo migratorio-laboral transnacional.

Hasta el momento, el aspecto más estudiado entre los migrantes senegaleses alrededor del mundo es la construcción de pertenencias religiosas asociadas a las cofradías islámicas sufíes $^{4}$ que caracterizan el islam al sur del Sahara, desde donde

${ }^{3} \mathrm{Me}$ adhiero al concepto de configuración cultural propuesto por Alejandro Grimson (2011). La propuesta de vinculación entre los componentes africano, musulmán y europeo la tomo de Malherbe y Sall (1989).

${ }^{4}$ Las cofradías o tariqas son hermandades islámicas sufíes con una organización, estructura y ritual específicos, cuya importancia se desarrolló desde el siglo XIX hasta el presente, no sólo en términos espirituales, sino también sociales, políticos y eco- 
se expandieron mundialmente por la migración internacional, a partir de mediados del siglo xx. La notoriedad de las cofradías llevó a algunos autores a postular que no sería correcto referenciar a este grupo migratorio en clave nacional, sino meramente religiosa. En este sentido, en vez de hablar de migrantes senegaleses, cabría denominarlos migrantes mourides (Lacomba 2001; Massó Guijarro 2014) —haciendo hincapié en la cofradía islámica propiamente senegalesa, hoy de existencia transnacional. Se enfatiza, entonces, que "otro tipo de identidades o lealtades (etnia, parentesco cercano...) se ven relegadas frente a la poderosa significación espiritual de ser murid" (Massó Guijarro 2014, 92).

Sin embargo, en mi propia investigación sobre las trayectorias laborales transnacionales de este grupo migratorio, he podido constatar que, aunque la categoría étnica tiene menos peso que la religiosa en la autorrepresentación de los entrevistados, cuando se indaga en imaginarios y prácticas del trabajo, entre algunos aparecen referencias a un saber-hacer sobre la fabricación y la venta de bijouterie que es heredado por nacimiento (Evers Rosander 2015), debido a la posición social que ocupa la familia en la estratificación wolof. Tradicionalmente basada en la división social del trabajo (Diop 1981), esta jerarquización “imprime a la sociedad contemporánea senegalesa sus características fundamentales" (Poulet 2016, 293; traducción propia).

Para la investigación empírica de este artículo utilicé una metodología cualitativa que incluyó una revisión bibliográfica especializada y un trabajo de campo etnográfico llevado a cabo en Argentina (principalmente en las ciudades de La Plata y Puerto Madryn), entre 2012 y 2018 con migrantes senegaleses, así como en Senegal en 2017 (ciudades de Dakar, Saint-Louis, Touba, Khombole, Mboro y Mékhé), con familiares y migrantes que se encontraban de visita en su país de origen. Las

nómicos (Costa Dias 2009). En Senegal encontramos principalmente la Muridiyya, la Tijanniya, la Qadriyya y la Layenne. 
principales técnicas de investigación empleadas incluyeron entrevistas abiertas y semiestructuradas en profundidad, así como observaciones participantes. ${ }^{5}$

Este artículo está organizado del siguiente modo: primero introduzco algunos datos relevantes sobre la República del Senegal y la migración senegalesa en Argentina, para luego enfocarme en las características de la organización social wolof tradicional y en ejemplos concretos extraídos de mi trabajo de campo, que muestran cómo esas referencias constituyen marcos de identificación y acción entre mis interlocutores senegaleses en la contemporaneidad.

\section{De Senegal a Argentina}

La República del Senegal, cuya capital es Dakar, se ubica al sur del Sahara y geográficamente es el país más occidental de África. ${ }^{6}$ La relación entre África subsahariana y América del Sur es de un ensamblaje continental evidente, vínculo que desde ya no es meramente geográfico, sino también geopolítico, al contener ambas regiones "[p]aíses en vías de desarrollo, periféricos, que comparten similares situaciones de vulnerabilidad y desafíos" (Lechini 2013, 64). Es decir, una historia de ocupación colonial y de luchas por las independencias que las posicionan en situaciones de dependencias y asimetrías respecto a los países hegemónicos. No obstante, los vínculos históricos con las metrópolis han sido disímiles, y hoy ambas subregiones son tan diferentes entre sí como la miríada de realidades socioculturales, políticas y económicas que abarcan (64).

Senegal comparte $800 \mathrm{~km}$ de frontera con varios países: Mauritania por el noreste, Mali por el este, Guinea Conakry y Guinea Bissau por el sur, mientras que en el oeste el océano

${ }^{5}$ Además de estas técnicas, la investigación incluyó una producción de imágenes en etnofotografías que, por motivos de espacio, aquí no fueron incluidas.

${ }^{6}$ Ubicado entre $12^{\circ} 8^{\prime}$ y $16^{\circ} 41^{\prime}$ de latitud norte y $11^{\circ} 21^{\prime}$ y $17^{\circ} 32^{\prime}$ de longitud oeste, y posee una extensión de $196722 \mathrm{~km}^{2}$ (ANSD 2016). 
Atlántico establece una frontera marítima de $530 \mathrm{~km}$. Situación particular es la de Gambia, país enclavado hacia el sur de Senegal, que bordea el río Gambia hasta su desembocadura (Diouf 2014). "“Cuando dibujo las fronteras de África siempre tengo la impresión de estar hiriendo pueblos', decía un geógrafo sobre los límites impuestos hace más de un siglo" (Rekacewicz 2013, 46). Aquí algunos de estos pueblos son el wolof, el serer y el mandinga, que, más allá de las fronteras negociadas (Mbembe 2008) durante el reparto europeo de África-que dejó como saldo en este caso un Senegal francés y un Gambia inglés-, comparten un área geográfica y ciertas características culturales a través de las fronteras, razón por la cual también se conoce como la región de Senegambia. 'La 'Senegambia' histórica es una región de África Occidental formada, desde mucho antes de la ocupación colonial, por múltiples convergencias históricas y por sucesivas 'urdimbres' políticas, religiosas, sociales y culturales" (Costa Dias 2009, 58).

La lógica colonial de base también impactó en la matriz productiva senegalesa actual, orientada principalmente a bienes de exportación ligados al sector primario extractivista. Si bien ahora es posible distinguir hasta siete sectores económicos, entre todos destaca el polo productor de maní en el centronorte del país (Ba 2016). Esta actividad, instalada desde 1841, originó una zona conocida como la cuenca del Maní, que, con los planes de ajuste estructural instrumentalizados por el Banco Mundial y el Fondo Monetario Internacional a partir de 1980, se erigió como una de las principales zonas de emigración del país (Sakho et al. 2015) y cuna de los modou-modou, expresión cuya etimología es el epítome mismo de la genealogía de la migración senegalesa. Antiguamente, modou-modou designaba a los campesinos wolofs mourides que migraban estacionalmente; hoy en día se usa para referirse a los migrantes senegaleses internacionales en general (Poulet 2016). Las remesas que envían al país estos últimos, se encuentran inyectadas en la economía senegalesa en orden de importancia fundamental, detrás de actividades como la pesca y el turismo (Crespo 2007). 
Senegal se divide administrativamente en 14 regiones, de las cuales la mitad abarca la mencionada cuenca del Maní, cuya zona central es el principal lugar de procedencia de mis interlocutores. Según las estadísticas oficiales, los migrantes de la región de Dakar corresponden al $30.3 \%$ de los emigrantes del país, mientras que los emigrantes de las regiones eminentemente agrícolas representan sumados $21.7 \%$ (ANSD 2014).

La población senegalesa es de 15726037 personas, con $50.2 \%$ de mujeres y $49.8 \%$ de varones. El $46.7 \%$ del total reside en centros urbanos y $53.3 \%$ en zonas rurales (ANSD 2019). La proporción de personas entre los 0 y los 18 años de edad es de $51 \%$, lo que evidencia un perfil poblacional joven, cuya esperanza media de vida al nacer es de 64.8 años (ANSD 2014). La diversidad étnica y cultural de este país es significativa; destacan seis grupos étnicos cuyos idiomas son considerados oficialmente lenguas nacionales (wolof, peul, serere, diola, mandinga y soninké). ${ }^{8} \mathrm{La}$ etnia wolof es mayoritaria en Senegal y se concentra en el centro del país, sobre todo en la cuenca del Maní -regiones de Diourbel y Louga- (Fall 2002; Fall y Garreta Bochaca 2012). Su lengua es hablada no sólo por gente wolof y lebou, ${ }^{9}$ sino también por $80 \%$ de la población senegalesa étnicamente diversa pero que lo entiende o lo habla, lo que le otorga el mote de "lengua vehicular" del conjunto de

${ }^{7}$ Incluye las regiones de Diourbel, Fatick y Kaolak, y partes de Thiès, Tambacounda y Louga y de la región de Dakar.

${ }^{8}$ Wolof $43 \%$ de la población, toucolor (también llamados peuls, halpulaares, fulbes o fulas) $24 \%$, serer $15 \%$, lebou $10 \%$, diola $4 \%$, mandinga $2 \%$. Aproximadamente el $2 \%$ restante abarca población de origen bassari, mauritana, mora, europea, libanesa y china (Evers Rosander 2015). Los relatos populares asocian el origen del nombre de Senegal a dos palabras en lengua wolof, sunu y gaal, cuya traducción es "nuestra piragua" (Malherbe y Sall 1989).

9 La bibliografía coincide en considerar a los lebous como parte de la etnia wolof (Malherbe y Sall 1989; Fall 2010), aunque algunos autores los definen como un grupo étnico específico (Laborde 1995). La primera postura los ubica en la región norte en torno al río Senegal, desde donde migraron antaño hasta instalarse definitivamente en los barrios costeros de Dakar, ya que tienen tradición pesquera. En su mayoría pertenecen a la cofradía islámica Layenne, menor en relación con las dominantes en Senegal (Muridiyya y Tijanniya). 
Senegal. ${ }^{10}$ En un trabajo clásico sobre el campesinado wolof, Celma Agüero planteaba que este grupo es el más importante de todo Senegal en términos económicos y políticos, y cuya "lengua de comercio" (Agüero 1978, 368) penetró en aldeas cercanas a centros estratégicos desde el punto de vista colonial y en la burocracia poscolonial.

Si bien la lengua oficial en Senegal es el francés, ${ }^{11}$ el wolof es el vehículo de expresión y comunicación cotidiano nacional. En la calle, en la televisión, las radios y las redes sociales, en los vínculos intersociales, esta lengua tiene una marcada presencia, como pude observar durante mi etnografía. Por ejemplo, en los noticieros o los programas de debate televisivos, las placas informativas están presentadas en francés, pero el conductor o la conductora transmite en simultáneo la misma noticia en wolof, que es comentada en esta lengua en el seno familiar.

Los movimientos migratorios wolofs dentro de Senegal se asociaron al trabajo estacional en las plantaciones de maní, a inicios del siglo xx. En la década de 1940 ya se documentó su movilidad hacia los centros urbanos, donde dominaron el sector comercial y desarrollaron formas de identificación urbanas atravesadas por la religiosidad (Ross 2011), en un país con $95 \%$ de musulmanes (Evers Rosander 2015). Esta característica se mantuvo también en la migración internacional, cuyas formas de organización cofrádica tan llamativas acapararon los análisis académicos al argumentar que el mouridismo tiene un papel central en la migración, lo que favorece la articulación transnacional de redes de pertenencia religiosa que sirven de base a la organización comercial.

Fuera de Senegal, estas migraciones se dirigieron primero hacia los países vecinos de África Occidental, luego, hacia 1970,

${ }^{10}$ Cabe recordar que en Gambia también hay gente wolof y allí es la lengua más hablada, aunque el grupo étnico homónimo se ubique en tercer lugar, luego del fula y del mandinga, que es el mayoritario, con 40\% de la población (Kebbeh 2013, en Altrogge y Zanker 2019).

${ }^{11}$ Dominado por los jóvenes y con una tasa de alfabetización de $45.4 \%$ entre la población de 10 años (ANSD 2014). 
se registraron en Europa, sobre todo en el sur (Francia, Italia y España), y hacia 1980 en América del Norte. Es en la virada del siglo XX al XXI cuando Sudamérica comenzó a posicionarse como un nuevo destino para las migraciones africanas subsaharianas en general —designadas como migraciones sur-sur (OIM 2013) - provenientes en su mayoría de países como Senegal, Nigeria, Ghana, Guinea, Camerún, Mali, Costa de Marfil, Togo, Liberia, Gambia y Sierra Leona.

En Argentina, el aumento de estos flujos se registró en los dos últimos censos nacionales. El del año 2001 había contabilizado un total de 1883 personas de origen africano, y para el censo de 2010 esa cantidad aumentó casi al doble (2738 africanos, de un total de 1805957 extranjeros). Entre los países de origen, Senegal representaba la mayor proporción, con 459 personas (INDEC 2012). Sin embargo, esta cifra subrepresenta la cantidad de senegaleses que hay en el país, y aunque tampoco haya otra cifra oficial más cercana a la realidad, la Asociación de Senegaleses Residentes en Argentina estimaba para esos años que el número superaba las 5000 personas.

De esta población de migrantes senegaleses me interesa destacar algunas características. Por un lado, su perfil altamente masculinizado - es decir, una alta proporción de varones por sobre la cantidad de mujeres-, que responde a las estrategias económicas familiares de origen, basadas en una persistente división hegemónica del trabajo por géneros. Por otro lado, se registra una ocupación principal en el comercio callejero de bijouterie de fantasía y productos de marroquinería a lo largo y ancho del país, con mayor concentración en la Provincia de Buenos Aires. ${ }^{12}$ Finalmente, cabe destacar su pertenencia a la religión musulmana (principalmente a las cofradías Muridiyya y Tijaniyya) y una identificación étnica wolof mayoritaria. ${ }^{13}$

${ }^{12}$ Para un mayor desarrollo de estos aspectos se pueden consultar mis trabajos anteriores (Espiro 2016, 2017, 2019a, 2019b).

${ }^{13} \mathrm{Me}$ baso en los presupuestos fundantes de Fréderik Barth (1976) acerca de la productividad de los límites y las fronteras de los grupos étnicos para pensar las identidades étnicas, entendidas como resultado de las relaciones cambiantes y disputadas 
Durante mi investigación encontré que la autopercepción como especialistas en bijouterie, esgrimida por algunos de mis interlocutores senegaleses wolofs que trabajan en el comercio callejero, tiene marcos de referencia en la estructura tradicional jerarquizada de la sociedad wolof y las pertenencias que ésta instauró. Es sobre esta articulación entre las variables étnica y laboral en lo que profundizaré a continuación.

\section{El estatus de bijoutier en la organización social wolof}

Los viajeros portugueses fueron los primeros que arribaron a la costa occidental de África hacia el siglo Xv, en ese entonces dominada por el imperio Djolof. De sus exploraciones datan los documentos escritos más antiguos que proveen información sobre personas de origen wolof. Pero éstos ofrecían un conocimiento eurocentrista sobre su sociedad, fragmentario y contradictorio, a partir de descripciones sobre cuestiones económicas y militares, y la preocupación sobre las instituciones y la organización social wolof era escasa (Malherbe y Sall 1989).

El mundo encontrado por los viajeros portugueses les parecía irreconocible. La enorme dificultad para entender a ese "otro" impuso los filtros europeo-cristianos para generar algún tipo de interpretación, en clave homogeneizante y monolítica. Esto se mantuvo constante a lo largo de la historia, sobre todo por la posterior influencia del paradigma hegeliano según el cual "África no es una parte histórica del mundo. No tiene movimientos, progresos a mostrar, movimientos históricos propios" (Fage 1985, en Arnaut y Lopes 2005, 36; traducción propia), sino hasta la llegada de los europeos al continente.

entre la auto y la heteroidentificación donde se producen, reproducen, disputan y transforman categorías y significaciones sociales. Recurro entonces a la noción de "identificación" porque connota lo que de dinámico, móvil, múltiple y performativo tienen estos procesos identitarios, siempre inteligibles desde determinados marcos de interlocución, en línea con los planteos de Bartolomé (2006), Giménez (2009) y Hall (2010), entre otros. 
Sin embargo, entre los siglos XVII y XIX, con la instalación de los puestos comerciales franceses, ingleses y holandeses, aumentaron las referencias sobre personas de origen wolof, aunque aquellas sobre su historia social permanecieron en segundo plano. Fue a partir de la necesidad de una ocupación permanente y de la demarcación del territorio durante la fase expansionista europea en África cuando se hicieron los primeros intentos de generar un conocimiento sistemático sobre este pueblo, en los que siguió prevaleciendo el punto de vista externo. Apenas a inicios del siglo XX se rescataron algunos exponentes de la tradición oral wolof que supieron conservar y transmitir conocimientos propios acerca de su historia, como Yoro Dyâo o Amadou Wade (Diop 1981).

Actualmente, hay consenso sobre la existencia, hacia finales del siglo XIII, de una organización social dominante en este territorio: el imperio Djolof, que unificaba grupos de etnia wolof y de cuya escisión, en el siglo xvi, se habrían originado reinos como el Waalo, el Cayor y el Baol, que se mantuvieron hasta el final del siglo XIX (Diop 1981; Malherbe y Sall 1989; Gentili 2012). ${ }^{14}$ Cada uno de éstos tenía un rey propio, pero entre todos compartían una estructura social similar. Es acerca de la naturaleza de esta estructura tradicional sobre la que hay diversas miradas, algunas más consolidadas que otras, aunque todas las posiciones concuerdan en que se trataba de una sociedad con jerarquías muy marcadas. Esto llevó a sostener que: "El análisis de las estructuras sociales de la sociedad wolof es más difícil de lo que se pensaba. Éstas aparecen por el modo de designación y jerarquía adoptado por los propios wolofs, lo que ha llevado a muchos autores a la definición de la sociedad wolof como una sociedad estratificada" (Diouf 1990, en Ogawa 2009, 125; traducción propia).

Algunas posturas la representan jerárquicamente como una organización piramidal en tres estratos: jaambur: nobles y gente

${ }^{14}$ Respeto la mención bibliográfica que presenta estas organizaciones sociopolíticas como imperios y reinos y sigo las definiciones de Arnaut y Lopes (2005) al respecto. 
común (campesinos, pescadores, pastores); ñeeño: especialistas artesanos (herreros, joyeros, zapateros y griots, entre otros) y jaam: esclavos (Gamble 1957). Varían las posturas acerca de si el ordenamiento es en función del origen étnico de cada sector o de los vínculos trazados en el periodo colonial y la acumulación de poder relativo. Otros autores plantean que se trataba de una sociedad jerarquizada y no igualitaria conformada por dos estratos, cada uno con una dinámica propia pero interrelacionados: el sistema de castas (especialistas) y el sistema de órdenes (gobierno) (Diop 1981). Finalmente, hay otros autores que concuerdan con esta última propuesta, pero advierten la necesidad de entender mejor la naturaleza del vínculo entre estratos en la estructura social wolof tradicional (Ogawa 2009).

La interpretación mediante dos sistemas que propuso el sociólogo y escritor senegalés Abdoulaye Bara Diop (1981) fue pionera y crucial para entender mejor la complejidad de esta sociedad. Se basa en las interpretaciones de principios del siglo xx de Yoro Dyâo y retoma la propuesta estructuralista clásica de Fortes y Evans-Pritchard (African Political Systems de 1940), donde se plantean diversos tipos de sociedades, y la wolof correspondería a la de tipo estatal o con una esfera de gobierno específica. En ésta, el parentesco tenía incidencia en la vida política en el ámbito de las unidades territoriales, pero había un aparato administrativo centralizado que controlaba la distribución de la riqueza. La heterogeneidad social se basaba en estatus desiguales, producto de una distribución dispar de esa riqueza; por ello, para el siglo xv la sociedad wolof mostraba una inequidad social bastante marcada. Así, lo que diversos autores distinguieron como un sistema político y un sistema social en la estructura tradicional wolof, coincide con lo que Diop llamó “sistema de órdenes" (geér) y "sistema de castas" (ñeeño), respectivamente, cada uno con fundamentos y características diferentes: el de castas representa la división del trabajo y el otro concentra el poder político. ${ }^{15}$

${ }^{15}$ El término "casta” para designar los distintos estratos de la sociedad tradicional wolof está ampliamente extendido, pero Ogawa (2009) sostiene que no hay consenso 


\section{Estructura social de los wolofs: esquematización por ejes de coordenadas tridimensionales}

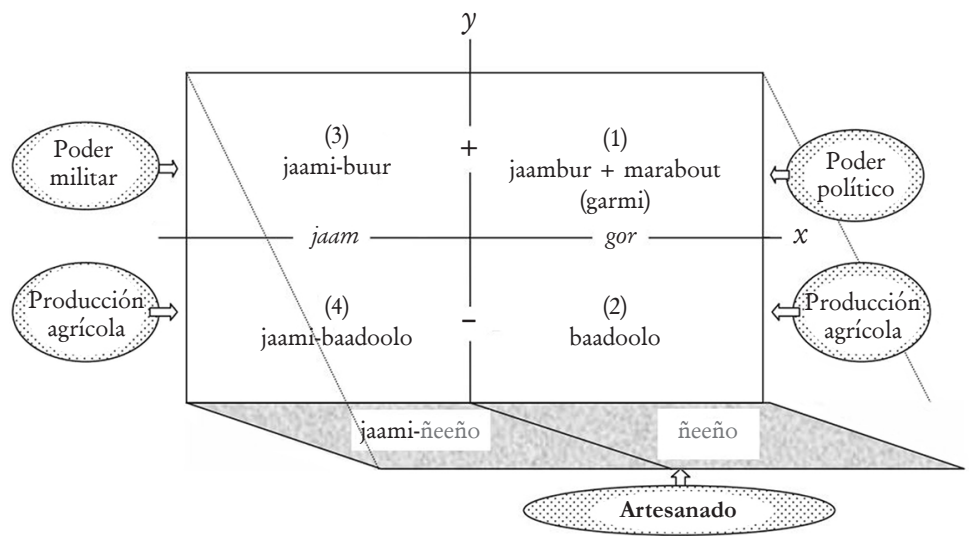

Fuente: Tomado de Ogawa, 2009, 126; traducción propia.

Integrando todos los estratos y los subgrupos considerados, el investigador japonés Ryo Ogawa (2009) propuso un esquema de esta organización social tradicional en el que explica las relaciones entre los diversos sectores. Sus argumentos para comprender a la sociedad wolof arrojaron luz para mi propio estudio, ya que ofrecieron explicaciones a referencias vigentes

ni definiciones claras. Malherbe y Sall (1989) sólo mencionan que su uso difiere del hindú, aunque comparte con éste la base de tradición y la idea de especificidad de cada grupo. Poulet (2016), por su parte, explica que en el siglo Xvir el término fue tomado por franceses e ingleses de los portugueses, que lo usaban para referirse a los grupos sociales de India. Los primeros lo aplicaron al contexto africano para designar los grupos sociales endógamos definidos por su especialidad profesional. Hoy está ampliamente extendido e incorporado al discurso común para representar la heterogeneidad social africana. La autora define entonces como casta, para África Occidental, a un grupo basado en un estatus y lo designa con el término wolof wadso, que también significa grupo de pertenencia. Esta autora hace hincapié en la dimensión procesual de la casta como una idea que tiene su correlato en el orden social, el cual es construido colectivamente mediante un proceso de elaboración de categorías sociales (castisation). Aquí sigo esta última postura. 
y resignificadas que aparecieron recurrentemente en el plano empírico en las identificaciones étnico-laborales de mis interlocutores senegaleses.

En su explicación esquematizada, Ogawa plantea que una primera gran oposición se daba entre los sectores con libertad $(\text { gor })^{16}$ y aquellos serviles (servilitê) (jaam) - eje de las abscisas-, mientras que la otra oposición ocurría entre quienes detentaban de mayor a menor poder político - eje de las ordenadas-. Así, el cuadrante 1 representa a los gobernantes (personas libres que gozaban de mayor poder de decisión). Se destaca que el autor incluye en este sector la participación y el protagonismo social de personalidades religiosas, los marabout, líderes de las cofradías islámicas. ${ }^{17}$ Según Ogawa, en la sociedad tradicional actuarían como asesores de gobierno, aunque se observa que, actualmente, se mantiene y complejiza esta función en el seno de las actividades económicas, como, por ejemplo, al constituirse como facilitadores de recursos económicos o de ayuda espiritual para los discípulos a cambio de fidelidad y apoyo (Fall 2011). Este grupo de nobles o señores (Crespo 2007; Sinatti 2014) habría desarrollado una ética de tipo feudal que, en épocas del colonialismo, se articulaba conflictivamente con los intereses de la metrópoli.

En el cuadrante 2 encontramos el sector de los campesinos: trabajadores agrícolas que no ocupaban posiciones políticas y

${ }^{16}$ Cabe advertir la ausencia de análisis de género en estas dinámicas sociales por parte de los autores, cuestión que de existir permitiría comprender mejor la intersección entre clase, trabajo y género en la migración senegalesa transnacional. No obstante, la palabra gor (del wolof) significa 'varón' (mientras que 'mujer' es djiguene); en este sentido es posible inferir preliminarmente - con base en estos argumentos que retoman los vocablos nativos- que la referencia para persona libre y con poder es androcéntrica. En cuanto a las mujeres, no hay mención al respecto.

${ }^{17}$ En lengua bereber, marabout significa "santo", y este término fue adoptado por la administración colonial francesa para designar a los líderes musulmanes de África Occidental. En Senegal se utiliza, junto con el de serigne, para nombrar a cualquier figura religiosa musulmana relevante, sin que necesariamente se le considere un santo, y se reserva el término sheikh para referirse a personalidades musulmanas notables con el estatus de transmisores de conocimiento místico (wird); en este sentido, su figura se acerca a la condición de santidad del marabout (López de Mesa Samudio 2008). 
que calificarían como personas libres, aunque estaban bajo el dominio de los nobles y de los esclavos de la nobleza. Estos últimos se ubican en el cuadrante 3 , lo que indica su alto grado de servilismo y poder al mismo tiempo, por su especialización en actividades defensivas. Por último, en el cuadrante 4 se ubicarían los más desaventajados en esta sociedad, los esclavos de los sectores campesinos, quienes también se ocupaban de tareas agrícolas.

Los dos sectores restantes en esta sociedad son de mayor interés aquí, ya que aportan elementos relevantes para comprender los procesos migratorio-laborales de los senegaleses wolofs en la contemporaneidad. Ogawa propone que se trata de dos secciones propiamente wolofs, pero con características diferentes a las demás al conformar un grupo de estatus profesional basado en especialidades laborales. ${ }^{18}$ Por un lado, el sector de los ñeeño incluye a diversos tipos de artesanos y a los griots (Evers Rosander 2015), entre los que también hay un subsector de servidumbre (jaami-ñeeño); ambos formarían estrictamente el sector de "castas". ${ }^{19}$ Este sistema de castas o grupos de estatus típico de la sociedad wolof tradicional aparece como una de las tantas líneas divisorias que organizan las relaciones actuales y la construcción de pertenencia, en el contexto de origen y destino de los migrantes senegaleses dedicados a la producción o comercialización de bijouterie. Por eso, a continuación, desarrollo con mayor profundidad las prácticas laborales específicas del sector de los ñeeño.

${ }^{18}$ Desecha así la tesis de otros autores que consideraron que no eran personas originariamente wolofs y que, por ello, habrían ocupado posiciones subordinadas frente a los demás sectores sociales en la estructura tradicional.

${ }^{19}$ Diouf (1990, en Ogawa 2009), siguiendo la propuesta de Diop (1981), define a los géér por oposición a los ñeeño como el sector no artesanal, y plantea que en el reino Kayor del siglo XIx los géér eran la "raza wolof, pura y superior", por oposición a las "castas extranjeras e inferiores" de ñeeño, haciéndose eco de la idea de que estos últimos eran un sector subordinado y originariamente no wolof. Otros autores que siguen a Diop, como Poulet (2016), sostienen que esta subordinación se perpetuaría hasta la actualidad, naturalizada mediante mecanismos representacionales, como la idea de pureza de sangre. 
En este sector se incluye a quienes viven de la palabra (gewël) y los artesanos (tëgg, trabajadores del metal; wunde, zapateros, marroquineros; raab, tejedores) (Diop 1981; Malherbe y Sall 1989; Sinatti 2014; Poulet 2016). El término gewël se traduce como griot, figura ampliamente descrita en la literatura sobre África Occidental, porque, en su pluralidad de sociedades, ejerce funciones relacionadas con la transmisión oral de los eventos sociales, de la historia familiar, las noticias. Antaño alentaban a los guerreros para el combate, y a su regreso los presentaban frente a su pueblo recitando loas sobre sus epopeyas. En el imaginario permanecen ligados a las familias de los nobles y de los campesinos como depositarios y transmisores de la memoria familiar, cuya genealogía recitan en las celebraciones en las que ofician como anfitriones, por cuyos servicios reciben alguna retribución en dinero. Son músicos y trovadores que, en los tiempos actuales, brindan sus servicios artísticos remunerados en diversos eventos de la sociedad senegalesa, fuera de la familia a la que están originalmente ligados. Un caso paradigmático es el del músico mundialmente famoso Youssou N'Dour, quien ha popularizado la música senegalesa en Occidente mediante un estilo que él mismo contribuyó a crear, el mbalax. En palabras de Omar, uno de mis interlocutores senegaleses en Argentina:

Gaulo es casi más o menos griot. Hay varios. Hay tëgg, gewël y gaulo; hay un poco de diferencia, porque cada uno tiene su característica. Antes, hay un viejo allá, muy reconocido en todo el país; se llama Samba Diabare, es un gaulo. Él hace un instrumento tipo guitarra, que se usa en Senegal, Mali y en algunos países de África. Tocaba y cantaba eso. Los gaulo no cantan las canciones de ahora como Youssou N'Dour, porque antes - estoy hablando del momento pasado-, cuando había rey, entonces esos eran la gente que están muy cerca del rey. Hay un proverbio wolof que dice eso: "que estaban más cerca del rey siempre". Siempre cuando hay rey, hay esclavo; hay combatientes que pelean y hay también los que cantaban, le dicen griot. Que si el rey tiene que mandar un mensaje a la gente, él lo dice, como el presidente ahora al porte-parole (portavoz). Los que hacían eso para el rey eran los griots. Ellos se van con su yembé, por ejemplo, con el tambor, hasta llamar la 
atención de todo el mundo y le pasaban el mensaje del rey. Y cuando había reunión, también; cuando se sientan todos, el griot le dice, por ejemplo: "Tu abuelo se fue a luchar por Francia en la Segunda Guerra Mundial, tu abuelo decía que mejor te quedes acá a morir en África. Dejar a Francia sufrir. Tu abuelo era una persona muy educada". Cuando alguien te dice eso, vos te sentís muy fuerte, triste, pero fuerte. Te dice siempre quién sos, para que no te metas en el mal camino. Cada familia lo tiene. Alguien que se ocupa de decirte las cosas con cariño. Más que si hay fiesta para agarrarte plata, te va a decir cosas feas, pero con cariño: "¡Mira cómo te vestiste hoy, vos sos el rey!" (Omar, La Plata, Argentina, 2018).

Para estos grupos de estatus, las celebraciones familiares y las fiestas religiosas recrean la lógica de las fiestas de los nobles (géér) de antaño, auspiciadas por griots amigos que recitan y cantan las hazañas de esa familia. Durante mi estancia etnográfica en Senegal, en ocasión de una fiesta de matrimonio a la que asistí como invitada, pude observar el papel de los griots, tanto los de la familia anfitriona como los contratados para amenizar la celebración, lo que evidencia la mercantilización actual del oficio.

Un grupo de tres músicos llegó desde la mañana cuando terminó de montarse la carpa que concentraría una parte del festejo en el patio de la casa, eran los griots contratados para musicalizar, como me dijera Sokhna [mujer migrante en Argentina que se encontraba de visita en Senegal]. Se acomodaron en sillas plásticas en un lateral de la carpa. Con palanganas plásticas, baldes de margarina vacíos y un megáfono, comenzaron a cantar y a tocar música para amenizar desde temprano. Hacia el mediodía, cuando la mayoría de los familiares invitados había llegado y estábamos terminando de comer, los griots de la familia comenzaron a cantar. Un señor anciano vestido de blanco con anteojos negros era coreado por una mujer que estuvo desde temprano ayudando en la preparación del almuerzo. Estos griots de la familia Thiam [apellido de la familia anfitriona] recuerdan la historia oral, o también se remontan con sus cantos a ese antepasado común entre los Seck y los Thiam [apellido de otra parte de esta familia extensa], según me contaron la hija y la hermana de Sokhna. Durante sus cantos mencionaban el nombre de algún invitado presente, lo que todos ovacionaban, y el invitado en cuestión se acercaba bailando para entre- 
garle dinero al griot de la familia (Diario de campo, Mékhé, Senegal, 2017).

Por otro lado, existe el grupo de los tëgg, los herreros u "hombres del metal; ellos pueden ejercer también el oficio de joyero (bijoutier)" (Malherbe y Sall 1989, 100; traducción propia)..$^{20}$ Cada herrero está también ligado a una familia de nobles o campesinos en un vínculo mucho más laxo que el que mantienen los griots con éstos, ya que no son depositarios de su historia familiar, pero sí participan de sus fiestas y están a su servicio. Del mismo modo, no reciben un salario, sino una suma de dinero a discreción. Desde ya, estos expertos en bijouterie colocan sus productos en el mercado de consumidores más amplio de la sociedad actual. Bamba, uno de mis principales interlocutores en Argentina, dedicado a la venta callejera de bijouterie de fantasía, recurrentemente comentaba que tenía experiencia en el rubro porque en Senegal (primero en Mékhé, su ciudad natal, luego en la capital del país) él trabajaba en sus propios locales de joyería. Como podemos leer en el siguiente extracto de entrevista:

B: Mi papá tiene un negocio, pero yo nunca fui [iba], de bijouterie, sí, grande. Mi papá me enseñar laburar bijouterie, enseñar mis hermanos, todos, ahora lo alquilan a una persona que fabrica ropa. Mi papá falleció hace mucho, ahora nueve años.

A: ¿Hacer bijouterie viene de una tradición, de gente que se dedica a eso? B: Sí, claro.

A: ¿Y cómo se llama esa gente?

B: Tëgg, solamente hay gente que puede hacer eso, gente especial, como géér, como geweël, como tëgg. Hay gente distinta en Senegal, yo soy tëgg. La gente gerwël siempre tocaron el tam-tam [tambor], gente especial, también. Mi familia es familia de tëgg.

A: ¿Cómo te enseñó tu papá a laburar en bijouterie?

${ }^{20}$ Según el Diccionario de la Real Academia Española (2019), "orfebre” es la "persona que labra objetos artísticos de oro, plata y otros metales preciosos, o aleaciones de ellos", sinónimo de "joyero", quien "hace o vende joyas". El Diccionario Larousse (2019) define bijouterie como "joyería” y bijoutier/tière como "joyero/a”, designaciones utilizadas por nuestros interlocutores senegaleses para referirse a estas labores. 
B: Aprendo yo, siempre fui para aprender al negocio de mi papá. Es un poco complicado para explicar eso, pero la fábrica tiene todo, tiene una máquina, si vos calentás la plata, ponés un cosito así y lo funde, ponés agua, ponés la plata, para agrandarlo, hacés anillos.

A: ¿Y vos hacías todo eso?

B: ¡Todo lo puede hacer yo! Estas cadenitas yo lo puede hacer - señala la bijouterie de fantasía que cuelga de un paño (Bamba, La Plata, Argentina, 2016).

De esta manera se inició Bamba en la producción artesanal de bijouterie, como parte de una crianza moldeada por disposiciones étnicas, de clase y ocupacionales específicas. Ndiaga, uno de los hermanos mayores de Bamba, ya se había ido de la ciudad de Mékhé en la década de 1990 para abrir, luego de unos años, sus propios locales en un barrio de Dakar. Él es dueño de dos boutique-atelier; ${ }^{21}$ en una produce y vende él mismo, $\mathrm{y}$ en la otra lo hace otro hermano mayor de la familia, con quien Bamba trabajó antes de emigrar a Argentina. Conversando con Ndiaga en uno de sus locales en Dakar, él me diría:

Hay ñeeño que hacen trabajo en hierro, como puertas; hay ñeeño que tienen talleres de aluminio; otros trabajan con madera, hacen muebles, camas, armarios. Pero la tradición del ñeeño es ésta, el trabajo en oro, plata, para la bijouterie, afirmaba Ndiaga en su local-taller de bijouterie en un barrio de la capital senegalesa. En un diploma enmarcado y colgado en su taller podía leerse en francés: "Diploma de Honor concedido al Señor Ndiaga Seck nacido el 04/05/1977 en Ngaye Mékhé por servicio rendido a la bijouterie senegalesa bajo el patrocinio del Ministerio de Artesanía y de la Industria” (Diario de Campo, Dakar, Senegal, 2017).

En ocasión de mi estadía en la ciudad de Mékhé, visité a la familia de Tonss, otro interlocutor oriundo de allí que conocí en Argentina:

Había cenado en su casa. Ya era de noche, así que las dos hijas de Tonss me acompañaron una parte del camino de regreso a la casa donde paraba.

${ }^{21}$ Del francés, a los locales comerciales en Senegal les llaman boutique, donde por lo general también se produce la bijouterie. Poseen un taller anexo para esto, el atelier. 
Vinieron también con nosotras una sobrina de él, casada con uno de los parientes que vive en Argentina, y la joven que vive en su casa y ayuda con las tareas domésticas. Caminábamos en la oscuridad, al costado de las vías del tren, sobre un sendero de tierra y bajo un cielo estrellado, cuando esta joven me preguntó cuál era mi apellido. Al responderle “Espiro", ella inmediatamente replicó: “¿Y eso qué es, ñeeño o qué?”. Aproveché entonces para mostrarme ignorante en el asunto y le dije que no sabía de qué me estaba hablando. Entonces, la sobrina de Tonss me explicó que "eso son como las etnias de Senegal. Nosotros somos ñeeño, desde nuestra historia. Hacemos esto, pulseras de metal, en oro y plata" (y me muestra la suya, que lleva grabado su nombre). "Ah, entonces los Thiam [apellido familiar] hacen joyería - repaso yo-. ¿Todos los Thiam?”, pregunto luego. “¡Claro!”, me responde. “¿Y qué otros hay?”. "Los gewël, que son músicos, cantan”. “¡Y luego?”. “Nada más”, concluyó (Diario de campo, Mékhé, Senegal, 2017).

En esta nota se observa, asimismo, que ciertos apellidos wolofs que se heredan por vía paterna están vinculados a la pertenencia ñeeño (Malherbe y Sall 1989). Siguiendo un estudio sobre patrónimos wolofs, la socióloga francesa Kelly Poulet sostiene: "[L]os Seck, ${ }^{22}$ Mbaye, Thiam, Diouf, por ejemplo, serían de condición social ñeeño, artesanos o griots [...] De hecho, si el nombre sigue siendo importante, las poblaciones senegalesas buscarán más para saber de qué familia específicamente se trata para identificar la historia del grupo de pertenencia” (Poulet 2016, 297; traducción propia).

Finalmente, la última de las castas consideradas por la bibliografía es la de los wuude, los curtidores del cuero y zapateros. En una entrevista realizada en Argentina a Tonss, él me comentaba respecto de su ciudad de origen:

Los mekheoirs, las personas que viven en Mékhé, son todos artesanos. Zapatos, ropas, joyería y muebles, esas cosas... y hay algunas cestas hechas a mano por ellos... no las suelo ver acá, hacen todo a mano... Mékhé es una ciudad muy particular en Senegal, todos la conocen. Primero, cuando decís Mékhé, la gente dice: 'Dallu Ngaay', eso es zapatos, lo que fabricamos allá, eso es lo que todos conocen de Mékhé: Dallu Ngaay.

${ }^{22}$ Éste es el apellido de Bamba y su hermano Ndiaga. Mientras que, como vimos, Tonss se apellida Thiam. 
'Dallu' es zapato y 'Ngaay' es Mékhé (Tonss, La Plata, Argentina, 2016).

\section{Reflexiones finales}

Contrario al estereotipo dominante en los medios de comunicación y entre la sociedad receptora mayor que muestra de manera homogeneizante y monolítica - y no es mera coincidencia que compartan la matriz de interlocución europea del imperialismo- a los migrantes oriundos de Senegal como "gente pobre que trabaja en la calle como vendedores ambulantes, porque es lo único que les queda para sobrevivir", en mi investigación antropológica, y de acuerdo con una metodología etnográfica, identifiqué una gran heterogeneidad de experiencias laborales vividas por los migrantes senegaleses en Argentina, ya que sus prácticas laborales se encuentran en una vinculación interdependiente con otras dimensiones que conforman su biografía en cada etapa del ciclo vital (migración, familia, religión, etnia, entre otras).

En este artículo puse el énfasis en la adscripción y la identificación de base étnica porque los migrantes de origen senegalés en Argentina, así como sus parientes en Senegal con quienes hice trabajo de campo, se reconocen étnicamente como wolofs. Para algunos, esto implica hablar la lengua de la mayoría de la población senegalesa y, sobre todo - aunque pocas veces explicitado-, pertenecer a una sociedad jerarquizada con base en una división del trabajo según la cual se pertenece por nacimiento a determinado grupo de estatus. Entre estos estratos destaca el de los griots (gewël) y, señaladamente, los especialistas en el trabajo con metales (tëgg): herreros, fabricantes y comerciantes de bijouterie que colocan sus productos en los mercados local e internacional. Estas disposiciones sociales les ofrecen recursos de diversa índole que usarán de manera estratégica para insertarse laboralmente durante el periplo migratorio, ya sea interno o internacional. Asimismo, habilitan otras vías 
de análisis respecto a sus prácticas laborales centradas en el comercio de bijouterie.

Cabe remarcar que no pretendo ofrecer aquí una visión culturalista de la sociedad wolof transnacional, puesto que, como mencioné, las características y la naturaleza del vínculo entre estos grupos de estatus se mantienen hasta la actualidad. ${ }^{23}$ Los procesos de islamización (iniciados en el siglo Ix), la economía de mercado y la urbanización introdujeron nuevos elementos, pero en lo esencial esta estructura, basada en la división del trabajo, no se modificó; antes al contrario, su condición desigual se acentuó (Diop 1981; Poulet 2016). Por eso, se trata de un aspecto fundamental para analizar la sociedad senegalesa contemporánea, no sólo en su origen, sino también en los destinos migratorios, como propongo aquí.

Un matiz ausente en los análisis de los autores abordados, que también quisiera destacar, es que no aluden a dinámicas de género en la organización social wolof tradicional que posibiliten profundizar en las dinámicas comerciales actuales de los migrantes senegaleses desde una perspectiva de género. ${ }^{24}$

${ }^{23}$ Para profundizar en las implicancias socioculturales de pertenecer a una sociedad jerarquizada en la que la subordinación se naturaliza mediante mecanismos como estigmatización y discriminación hacia los ñeeño, véase el análisis de Poulet, 2016. Esto puede constituir una línea de indagación sobre la escasa referencia a la variable étnica entre los actores sociales y, consecuentemente, en los estudios especializados. Para un análisis sobre las formas en que los ñeeño capitalizan estas relaciones asimétricas heredadas en sus prácticas comerciales con turistas europeos en Senegal, véase Georg Materna, “'Two Tribes of Capitalists': Neoconomists and Politiconomists in a Senegalese Marketplace”. FocaalBlog, 26 de marzo de 2018.

${ }^{24}$ La socióloga senegalesa Fatou Sow Sarr está recuperando esas figuras femeninas para documentar la presencia histórica de mujeres en puestos de gobierno (géér) antes de la islamización y la colonización, que según Sarr son los modelos que instauraron el patriarcado en esta región africana. Destaca la figura de Ndatté Yalla, reina de Walo hasta el ataque del gobernador francés Fahiderbe en 1855, cuando cayó definitivamente este reino wolof (Daumas 2014; Samb y Barreto Farias 2019). No obstante, las prácticas de mujeres ñeeño casi no han sido estudiadas. Poulet (2016) documenta en su estudio el caso de las mujeres griots en la actualidad, pero no he encontrado referencias históricas o actuales sobre los roles de mujeres tëeg, es decir, pertenecientes al estrato de especialistas en bijouterie. 
Finalmente, sin desestimar la situación de la mayoría de los migrantes africanos incorporados periféricamente al capitalismo tardío - por ejemplo, en mercados de trabajo segmentados-, llama la atención la escasa valoración de las referencias étnicas para analizar ciertas dinámicas senegalesas de migración y comercio presentadas en este trabajo. Esto puede deberse al sesgo de los relatos coloniales dominantes que invisibilizaron la historia del pueblo wolof, o a la relativa escasez de investigaciones al respecto en lengua española. Sea como fuere, espero que este análisis ofrezca una contribución en ese sentido para una mejor comprensión de la complejidad social de las migraciones africanas contemporáneas hacia América del Sur.

\section{Referencias}

AgÜERO, Celma. 1978. "Campesinado e islam: algunas reflexiones sobre el caso de Senegal”. Estudios de Asia y África 13, núm. 3 (septiembre-diciembre): 361-374. https://estudiosdeasiayafrica. colmex.mx/index.php/eaa/article/view/599/599

Altrogge, Judith y Franzisca Zanker. 2019. The Political Economy of Migration Governance in the Gambia. Friburgo: Arnold-Bergstraesser Institute. https://www.medam-migration. eu/publications/research-papers/2019-research-papers/thepolitical-economy-of-migration-governance-in-the-gambia-14224/

ANSD (Agence Nationale de la Statistique et de la Démographie). 2014. Rapport Définitif du Recensement Général de la Population et de l'Habitat, de l'Agriculture et de l'Elevage 2013. Dakar: Ministère de l'Économie, des Finances et du Plan. http://www.ansd.sn/ ressources/rapports/Rapport-definitif-RGPHAE2013.pdf

ANSD (Agence Nationale de la Statistique et de la Démographie). 2016. Recensement Général de la Population et de l'Habitat, de l'Agriculture et de l'Elevage (RGPHAE) 2013. Atlas Démographique du Sénégal. Rapport Final. Dakar: Ministère de l'Économie, des Finances et du Plan. http://www.statsenegal.sn/actualitesstatistiques-de-1-ansd/item/237-atlas-demographique-du-senegalrapport-final.html 
ANSD (Agence Nationale de la Statistique et de la Démographie). 2019. La population du Sénégal en 2018. Dakar: Ministère de l'Économie, des Finances et du Plan. http://www.ansd.sn/ressources/publications/Rapport_population_060219\%20002\%20 RECsn\%20.pdf

Arnaut, Luiz y Ana Mónica Lopes. 2005. História da África: uma introdução. Belo Horizonte: Crisálida.

BA, Boubacar. 2016. “Territorialisation du développement local au Sénégal : impensés, cheminements, enjeux et limites d'un concept et d'une aproche". En Les sciences sociales au Sénégal: mise à l'épreuve et nouvelles perspectives, dirigido por Mamadou Diouf y Souleymane Bachir Diagne, 67-96. Dakar: Conseil pour le développement de la recherche en sciences sociales en Afrique.

Babou, Cheikh Anta. 2015. "The Murid Ethic and the Spirit of Entrepreneurship: Faith, Business and Mobility among Murid Immigrants in Gabon”. DRI Annual Conference 2015: Beyond The Nation State, Nueva York, 13 de marzo.

BARTH, Fredrik, comp. 1976. Los grupos étnicos y sus fronteras: la organización social de las diferencias culturales. Traducido por Sergio Lugo Rendón. México: Fondo de Cultura Económica.

Bartolomé, Miguel A. 2006. "Los laberintos de la identidad. Procesos identitarios en las poblaciones indígenas”. Avá, núm. 9 (agosto): 28-48. http://www.scielo.org.ar/pdf/ava/n9/n9a03.pdf

BAva, Sophie. 2003. "De la 'baraka aux affaires' : ethos économicoreligieux et transnationalité chez les migrants sénégalais mourides". Revue Européenne des Migrations Internationales 19, núm. 2: 69-84. http://doi.org/10.4000/remi.454

Ceamanos, Roberto. 2016. El reparto de África. De la Conferencia de Berlín a los conflictos actuales. Madrid: Catarata.

CosTa Dias, Eduardo. 2009. "Cofradías musulmanas y movimiento de Da'wa: dos concepciones del islam en África occidental”. En El islam del África Negra, editado por Ferrán Iniesta, 39-59. Barcelona: Bellaterra.

Coulon, Christian. 1981. “Les marabouts idéologiques”. Politique africaine 4 (diciembre): 111-114. http://www.politique-africaine.com/ numeros/pdf/004111.pdf

Crespo, Rafael. 2007. “Los 'móodu-móodu' y su impacto en la sociedad de origen”. En Empresariado étnico en España, coordinado 
por Joaquín Beltrán, Laura Oso y Natalia Ribas Mateos, 249-261. Madrid: Ministerio de Trabajo y Asuntos Sociales.

Daumas, Cécile. 2014. “Au Sénégal, les femmes gouvernaient” [entrevista a Fatou Sarr]. Libération, 26 de mayo de 2014.

De Diego González, Antonio. 2019. Sufismo negro. Una breve historia del sufismo en África Occidental. Córdoba: Almuzara.

Diop, Abdoulaye-Bara. 1981. La famille wolof. Tradition et changement. París: Karthala.

Diouf, Jean-Léopold. 2014. Wolof. Chennevières-sur-Marne: Assimil. Espiro, María Luz. 2016. "De Buenos Aires a la costa chubutense: una aproximación etnográfica a la movilidad estacional de migrantes senegaleses". En Jornadas. Un siglo de migraciones en la Argentina contemporánea: 1914-2014, compilado por Nadia de Cristóforis y Susana Novick, 867-886. Buenos Aires: Universidad de Buenos Aires. http://biblioteca.clacso.edu.ar/Argentina/iigguba/20170530080906/LibroMigraciones_compr.pdf

EsPiro, María Luz. 2017. "Senegaleses entre la Argentina y el sur de Brasil: etnografía de la movilidad regional y la alternancia laboral entre venta ambulante e industria". En Africanos y afrodescendientes en la Argentina: prácticas, representaciones, narrativas y memorias, coordinado por Marta Maffia y Bernarda Zubrzycki, 41-60. Buenos Aires: Biblos.

Espiro, María Luz. 2019a. "Trayectorias laborales de migrantes entre África y Latinoamérica: el caso de los senegaleses en Argentina". Revista Interdisciplinar da Mobilidade Humana 27, núm. 56 (mayo-agosto): 81-98. https://doi.org/10.1590/198085852503880005605

EsPIRO, María Luz. 2019b. "Mujeres senegalesas en Argentina: notas sobre migración, regularización, asociacionismo y trabajo". En Mujeres migrantes (dossier). Buenos Aires: Instituto Nacional contra la Discriminación, la Xenofobia y el Racismo. http://inadi.gob.ar/contenidos-digitales/wp-content/uploads/2019/11/ MUJERES-MIGRANTES.pdf

EsPIRO, María Luz. 2019c. "Trayectorias laborales de migrantes senegaleses en La Plata y Puerto Madryn: una etnofotografía de los imaginarios y prácticas en torno al trabajo (2012-2018)". Tesis de doctorado. Universidad Nacional de La Plata.

Evers Rosander, Eva. 2015. In Pursuit of Paradise. Senegalese Women, Muridism and Migration. Upsala: The Nordic Africa Institute. 
Fall, Abdou Salam. 2011. "Les usages des liens confrériques religieux dans l'économie sénégalaise". En Islam et engagements au Sénégal : résultats d'un programme de recherche demandé par l'A mbassade du Royaume des Pays-Bas à Dakar, dirigido por Mayke Kaag, 47-79. Leiden: Centre d'Etudes Africaines.

Fall, Papa Demba. 2002. "Ethnic and Religious Ties in an African Emigration. Senegalese Immigrants in the United States". Studia Africana 13 (abril): 81-90.

FALl, PapaDemba.2010. Sénégal. Migration, marchédu travailleet développement. Ginebra: Organisation internationale du Travail. https:// www.academia.edu/3434031/S\%C3\%A9n\%C3\%A9gal_Migration_march\%C3\%A9 du_travail_et_d\%C3\%A9veloppement

FALL, Papa Demba y Jordi Garreta Bochaca, eds. 2012. Les migrations africaines vers l'Europe. Entre mutations et adaptation des acteurs sénégalais. Dakar: REMIGRAF-IFAN/GR-ASE.

FORTES, Meyer y Edward E. Evans-Pritchard, eds. 2010 [1940]. Sistemas politicos africanos. México: Universidad Autónoma Metropolitana. http://www.librosoa.unam.mx/xmlui/handle/ 123456789/1645

Gamble, David Percy. 1957. The Wolof of Senegambia. Together with Notes on the Lebu and the Serer. Londres: International African Institute.

Gentili, Anna Maria. 2012. El león y el cazador: historia del África subsahariana. Traducido por Carlos Catroppi. Buenos Aires: Consejo Latinoamericano de Ciencias Sociales.

GimÉNEZ, Gilberto. 2009. “Cultura, identidad y memoria. Materiales para una sociología de los procesos culturales en las franjas fronterizas”. Frontera Norte 21, núm. 41 (enero-junio): 7-32. https:// doi.org/10.17428/rfn.v21i41.972

Grimson, Alejandro. 2011. Los límites de la cultura. Crítica de las teorías de la identidad. Buenos Aires: Siglo XXI.

GuÈYE, Cheikh y Abdourahmane Seck. 2011. "Islam et politique au Sénégal : logique d'articulation et de co-production”. En Islam et engagements au Sénégal: résultats d'un programme de recherche demandé par l'A mbassade du Royaume des Pays-Bas à Dakar, dirigido por Mayke Kaag, 13-44. Leiden: Centre d'Etudes Africaines.

Hall, Stuart. 2010. Sin garantías. Trayectorias y problemáticas en estudios culturales. Editado por Eduardo Restrepo, Catherine Walsh y Víctor Vich. Bogotá: Universidad Javeriana. 
INDEC (Instituto Nacional de Estadística y Censos) (Argentina). 2012. Censo nacional de población, hogares y viviendas 2010. Censo del Bicentenario: resultados definitivos, Serie B No 2. Tomo 2. Buenos Aires: INDEC. https://www.indec.gob.ar/ftp/cuadros/ poblacion/censo2010_tomo2.pdf

INIESTA, Ferrán. 2009a. "Los caminos del islam al sur del Sahara". En El islam del África negra, editado por Ferrán Iniesta, 9-12. Barcelona: Bellaterra.

INIESTA, Ferrán. 2009b. "Mil años de islam negroafricano". En $E l$ islam del África negra, editado por Ferrán Iniesta, 15-38. Barcelona: Bellaterra.

LABORDE, Cécile. 1995. La confrérie layenne et les Lébou du Sénégal. Islam et culture traditionnelle en Afrique. Talence: Université Montesquieu-Bordeaux IV.

LacombA, Joan. 2001. "Inmigrantes senegaleses, islam y cofradías". Revista Internacional de Sociología 59, núm. 29 (mayo-agosto): 163-187. https://doi.org/10.3989/ris.2001.i29.760

LeChINI, Gladys. 2013. "Construyendo puentes sobre el Atlántico". En África: conflictos y esperanzas, editado por Pablo Stancanelli, 63-67. Buenos Aires: Le Monde diplomatique.

LóPEZ de MeSA SAMUdio, Julián. 2008. "Una foto para alcanzar a Dios: pistas acerca de la iconografía muridista". Historia y Sociedad, núm. 15 (julio-diciembre): 115-141. https://revistas.unal.edu. co/index.php/hisysoc/article/view/23481

Malherbe, Michel y Cheikh Sall. 1989. Parlons wolof. Langue et culture. París: L'Harmattan.

MAssó Guijarro, Ester. 2014. "Islam y género en la diáspora murid: mirada poscolonial a feminismos y migraciones". Methaodos. Revista de Ciencias Sociales 2, núm. 1: 88-104. https://doi.org/ 10. $17502 / \mathrm{m}$. rcs.v2i1.40

MвEMBe, Achille. 2008. "Al borde del mundo. Fronteras, territorialidad y soberanía en África”. En Estudios poscoloniales. Ensayos fundamentales, compilado por Sandro Mezzadra y traducido por Marta Malo, 167-195. Madrid: Traficantes de Sueños.

O’Brien CRuise, Donal. 2002. "Le sens de l'État au Sénégal”. En Le Sénégal contemporain, dirigido por Momar-Coumba Diop, 501506. París: Karthala. 
Ogawa, Ryo. 2009. "Pour une meilleure compréhension de la structure sociale des wolofs". Journal of Asian and African Studies, núm. 78: 113-130.

OIM (Organización Internacional para las Migraciones). 2013. Informe sobre las migraciones en el mundo 2013: el bienestar de los migrantes y el desarrollo. Ginebra: OIM. https://publications.iom.int/ system/files/pdf/wmr2013_sp.pdf

OIM (Organización Internacional para las Migraciones). 2017. Recientes tendencias migratorias extra e intra-regionales y extra-continentales en América del Sur. Informe Migratorio Sudamericano, núm. 2. Buenos Aires: OIM. https://robuenosaires.iom.int/sites/default/ files/Documentos\%20PDFs/Recientes_tendencias_migratorias_extra_e_intra_regionales_y_extra_continentales_en_america_del_sur_es.pdf

Poulet, Kelly. 2016 . "L'hypothèse migratoire comme horizon d'émancipation ? Une ethnographie des jeunesses dakaroises". Tesis de doctorado. Université de Picardie Jules Verne.

ReKaCEWICZ, Philippe. 2013. "Una geopolítica en permanente evolución”. En Africa: conflictos y esperanzas, editado por Pablo Stancanelli, 46-47. Buenos Aires: Le Monde diplomatique, 2013. Riccio, Brunúm. 2004. "Transnational Mouridism and the Afro-Mus$\lim$ Critique of Italy”. Journal of Ethnic and Migration Studies 30, núm. 5: 929-944. https://doi.org/10.1080/1369183042000245624 Ross, Eric. 2011. "Globalising Touba: Expatriate Disciples in the World City Network". Urban Studies 48, núm. 14 (noviembre): 2929-2952. https://doi.org/10.1177/0042098010391300

SAKHo, Pape, Rosalie Aduayi Diop, Bara Mboup y Diodio Diadiou. 2015. "A emigração internacional senegalesa: das casas no campo ás ciudades litorâneas”. En Migrações internacionais. O caso dos senegaleses no sul do Brasil, organizado por Vania Beatriz Merlotti Herédia, 23-49. Caxias do Sul: Belas-Letras.

SAMB, Fatime y Juliana Barreto Farias. 2019. "Entrevista com Fatou Sow Sarr”. Capoeira. Revista de Humanidades e Letras 5, núm. 1: 103-110.

SinAtTI, Giulia. 2014. "Masculinities and Intersectionality in Migration: Transnational Wolof Migrants Negotiating Manhood and Gendered Family Roles”. En Migration, Gender and Social Justice. Hexagon Series on Human and Environmental Security and Peace, vol. 9, editado por Thanh-Dam Truong, Des Gasper, Jeff 
Handmaker y Sylvia I. Bergh, 215-226. Berlín: Springer Open. https://doi.org/10.1007/978-3-642-28012-2_11

Wood, Ellen Meiksins. 1983. "El concepto de clase en E. P. Thompson”. Cuadernos Políticos, núm. 30 (abril-junio): 87-105. http:// www.cuadernospoliticos.unam.mx/cuadernos/contenido/ CP.36/CP.36.9.EllenMeiksinsWood.pdf

ZuBRZYCKI, Bernarda. 2011. "La migración senegalesa en Buenos Aires: el papel de las dahiras mourides en el proceso de anclaje local". En Migraciones internacionales contemporáneas. Estudios para el debate, coordinado por Cynthia Pizarro, 187-204. Buenos Aires: Ciccus.

M. Luz Espiro es licenciada en antropología y doctora por la Universidad Nacional de La Plata (UNLP). Realizó su tesis doctoral sobre una etnofotografía de las trayectorias laborales transnacionales de migrantes senegaleses en Argentina. Se desempeñó como docente universitaria en la Cátedra Etnografía II (UNLP), adscrita a la Cátedra de Historia de Asia y África (Universidad de Buenos Aires), y como docente en escuela media en el Proyecto de Investigación en Ciencias Sociales (IDB). Integra el Grupo de Investigaciones sobre Migraciones Africanas y Afrodescendencia en Argentina (División Etnografía, Facultad de Ciencias Naturales y Museo, UNLP) y el Archivo Audiovisual Observatorio Sur, como directora de Relaciones Institucionales con el África Subsahariana. Sus áreas de investigación son: migraciones africanas en Sudamérica, con especialidad en las senegalesas, trabajo, transnacionalismo y antropología visual.

$$
\begin{array}{r}
\text { https://orcid.org/0000-0001-8122-6981 } \\
\text { mluzespiro@gmail.com }
\end{array}
$$


